\section{RMD Open}

Rheumatic \&

Musculoskeletal Diseases
To cite: Garrido-Cumbrera M, Gálvez-Ruiz D,

Delgado-Domínguez CJ, et al. Impact of axial spondyloarthritis on mental health in Europe: results from the EMAS study. RMD Open 2021;7:e001769. doi:10.1136/ rmdopen-2021-001769

Received 10 June 2021 Accepted 5 October 2021

Check for updates

C) Author(s) (or their employer(s)) 2021. Re-use permitted under CC BY-NC. No commercial re-use. See rights and permissions. Published by BMJ.

${ }^{1}$ Health and Territory Research (HTR), University of Seville, Sevilla, Spain

${ }^{2}$ Charité Universitätsmedizin, Berlin, Germany

${ }^{3}$ German Rheumatism Research Centre, Berlin, Germany

${ }^{4}$ University Hospital La Paz, IdiPAZ, Madrid, Spain

${ }^{5}$ Patient Engagement, Novartis Pharma AG, Basel, Switzerland

${ }^{6}$ Axial Spondyloarthritis

International Federation (ASIF), London, UK

${ }^{7}$ Cyprus League Against Rheumatism, Nicosia, Cyprus ${ }^{8}$ Cardiff University, Wales, UK

Correspondence to Professor Marco GarridoCumbrera; mcumbrera@us.es

\title{
Impact of axial spondyloarthritis on mental health in Europe: results from the EMAS study
}

Marco Garrido-Cumbrera (1) , ${ }^{1}$ David Gálvez-Ruiz, ${ }^{1}$ Carlos J Delgado-Domínguez, ${ }^{1}$ Denis Poddubnyy (D) , ${ }^{2,3}$ Victoria Navarro-Compán, ${ }^{4}$ Laura Christen, ${ }^{5}$ Raj Mahapatra, ${ }^{6}$ Souzi Makri, ${ }^{7}$ Christine Bundy, ${ }^{8}$ on behalf of the EMAS working group

\section{ABSTRACT}

Objective To determine the presence of mental disorder risk and associated factors in European patients with axial spondyloarthritis (axSpA).

Methods Data from 2,166 patients with axSpA in 12 European countries were collected from 2017 to 2018 through the European Map of Axial Spondyloarthritis online survey. Risk of mental disorders was assessed using the 12-item General Health Questionnaire. Possible predictors included age, gender, relationship status, patient organisation membership, job status, educational level, Bath Ankylosing Spondylitis Disease Activity Index (BASDAl), functional limitation (0-54) and self-reported depression or anxiety. Bivariate analyses were conducted to determine predictors of risk of mental disorders (MannWhitney and $\chi^{2}$ ) and multivariable analysis identified factors associated with risk of mental disorders. Results $60.7 \%$ of patients reported risk of mental disorders: they were younger (41.7 vs 46.0 years), more likely female $(68.2 \%$ vs $57.9 \%)$, unemployed $(7.5 \%$ vs $2.7 \%)$, on temporary (15.9\% vs $5.4 \%$ ) or permanent sick leave (13.2\% vs $8.0 \%$ ), reported depression $(45.2 \%$ vs $14.2 \%)$ or anxiety ( $41.3 \%$ vs $12.5 \%)$, higher disease activity (BASDAI $\geq 4 ; 87.6 \%$ vs $62.3 \%$ ) and functional limitation (16.5 vs 10.8). The factors most associated with risk of mental disorders were disease activity $(\mathrm{OR}=2.80)$, reported depression ( $\mathrm{OR}=2.42)$, anxiety $(\mathrm{OR}=2.39)$, being unemployed or on sick leave $(\mathrm{OR}=1.98)$, functional limitation $(\mathrm{OR}=1.02)$ and younger age $(\mathrm{OR}=0.97)$. Conclusions Compared with the general population, patients with axSpA show disproportionately worse mental health associated mainly with disease activity and employment status. Healthcare professionals should pay close attention to patients with high disease activity and address internally or refer to specialist services, where appropriate to ensure optimal patient outcomes.

\section{INTRODUCTION}

Axial spondyloarthritis (axSpA) is a long-term condition characterised by loss of mobility, chronic pain and fatigue, reduced quality of life $^{1}$ and both physical and mental health. ${ }^{2}$

\section{Key messages}

What is already known about this subject?

- Poor mental health in patients with axial spondyloarthritis (axSpA) is associated with disease outcomes and worsening functioning.

What does this study add?

- The present study assesses mental health in a large sample of 2166 patients with axSpA in 12 European countries through the diagnosis of anxiety and depression and by means of the validated scale: the 12-item General Health Questionnaire.

- $60.7 \%$ of patients with axSpA in Europe had the risk of mental disorder, and the factors most associated were disease activity, being unemployed or on sick leave, greater functional limitation in daily activities and younger age.

- $30.0 \%$ reported previous experience of anxiety and $33.1 \%$ depression, these figures being six times greater among patients with axSpA in comparison with $5.4 \%$ and $4.5 \%$, respectively in the general population in Europe.

How might this impact on clinical practice or future developments?

- The results suggest the need to improve the mental well-being of patients with axSpA by monitoring their disease activity as well as early referral to mental health specialists.

Although the association between axSpA and high levels of distress (anxiety and depression) has been investigated, ${ }^{3}$ few larger-scale studies have confirmed this link. Methodological differences across studies in measuring common mental disorders yield varying approximations, with the presence of depression ranging between $11 \%$ and $64 \%,{ }^{3}$ and anxiety between $15.6 \%$ and $60.9 \% .{ }^{45}$ This is further complicated as regular assessment of mental disorders within clinical practice is yet to be applied systematically in axSpA care. 
It is well established that depression and anxiety are associated with increased disease activity in axSpA, chronic pain reporting and worsen functioning leading to poor health outcomes and quality of life. ${ }^{67}$ Previous studies have found that the factor most associated with the psychological health status of patients with axSpA was disease activity, although these findings need to be confirmed in a real-world sample. ${ }^{89}$

The European Map of Axial Spondyloarthritis (EMAS) aimed to capture factors influencing patients' perspective of the burden of axSpA, in different European countries using validated measures. ${ }^{2}$ Unlike other studies, which tend to rely heavily on clinical records and patients presenting to rheumatologists, the EMAS survey allowed for the collection of real-world data focused on parameters deemed relevant by patients with axSpA. Furthermore, it took a comprehensive view in assessing mental health, including both self-reported diagnosed comorbidities as well as scores from the 12-item General Health Questionnaire (GHQ-12) - termed mental disorder here.

Using the EMAS data, the aim of this analysis was to determine the presence of risk of mental disorders in European patients with axSpA and to examine associated factors.

\section{MATERIALS AND METHODS}

Study design

EMAS was a cross-sectional online survey of patients with a self-reported diagnosis of axSpA encompassing 13 European countries: Austria, Belgium, France, Germany, Italy, the Netherlands, Norway, Russia, Slovenia, Spain, Sweden, Switzerland and the UK. The survey was adapted from the Spanish Atlas of Axial Spondyloarthritis 2017, ${ }^{10}$ the results of which were added retrospectively to the EMAS database. The methodology of the EMAS study is described in detail elsewhere. ${ }^{2}$ For the purpose of this analysis on mental health, data from Spain were excluded as they have been previously published, ${ }^{9}$ therefore our final sample size presented here is 2,166.

All patients who agreed to their participation through informed consent, were asked to provide explicit opt-in consent prior to participating in the EMAS survey. The participant data collected in the survey does not allow the identification of individual participants. In this study, no clinical trial was conducted. As it was not an interventional study, no ethics committee approval was required.

\section{Working group}

The EMAS project is a collaboration led by the Health \& Territory Research group of the University of Seville, Axial Spondyloarthritis International Federation, Novartis Pharma AG and a steering committee composed of patient research partners and internationally recognised rheumatologists, psychologists and researchers specialised in axSpA.

\section{Patients}

Participants were recruited between July 2017 and March 2018 by Ipsos SA (formerly GfK), a market research agency, through their existing database of respondents. Patient advocacy groups supported recruitment by distributing the survey to their members in the following countries: Austria, Italy, the Netherlands, Norway, Russia, Slovenia and Sweden (figure 1).

The inclusion criteria were age $\geq 18$ years, resident in one of the participating countries, a self-reported clinician-provided diagnosis of axSpA, including

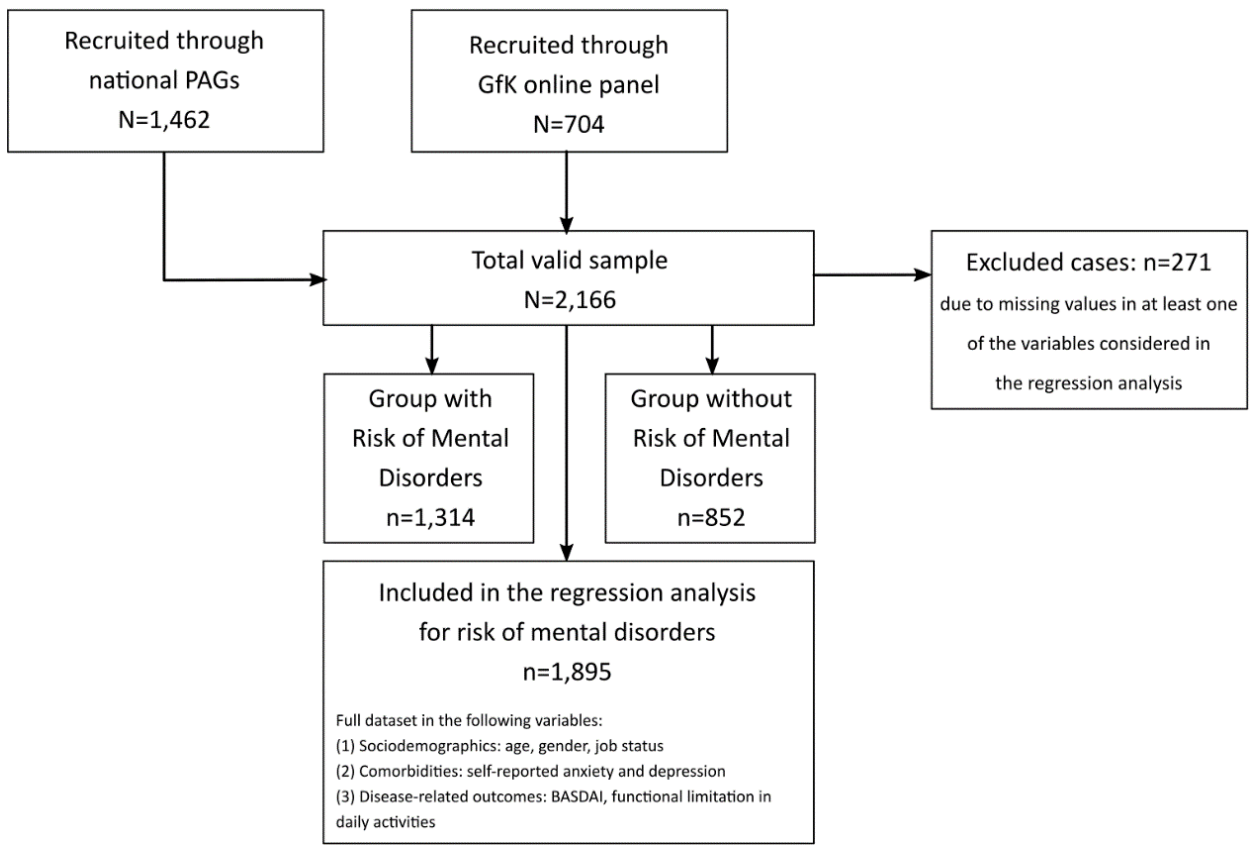

Figure 1 EMAS sample selection flow chart. BASDAI, Bath Ankylosing Spondylitis Disease Activity Index; EMAS, European Map of Ankylosing Spondyloarthritis; GfK, market research agency currently known as Ipsos SA; PAG, patient advocacy group; mental disorder risk (defined as 12-Item General Health Questionnaire score $\geq 3$ ). 
ankylosing spondylitis or non-radiographic axSpA and visit to a healthcare professional for axSpA in the 12 months prior to participation.

\section{Measurement}

The survey consisted of 108 items related to 12 different areas: sociodemographic and anthropometric characteristics, disability assessment, working life, daily life, lifestyle habits, diagnostic journey, healthcare utilisation, treatment, comorbidities (including extraarticular manifestations), mental health, axSpA-specific outcomes and patient disease-related attitudes and treatment goals. All variables collected for the EMAS survey were patient-reported.

\section{Patient-reported outcome measures}

We were mindful of the need to capture physical, psychological and social impact, while avoiding measurement fatigue and the risk of increasing social response bias. Therefore, we used both validated, commonly used measures and one developed with patients for the purpose of this survey. EMAS employed ${ }^{2}$ the Bath Ankylosing Spondylitis Disease Activity Index (BASDAI) to assess disease activity. Furthermore, to assess functional limitation, a non-validated tool referred to as the Functional Limitation Index, was specifically developed, with patients, for this study. The Functional Limitation Index assessed the degree of functional limitation in 18 activities of daily life (ie, dressing, bathing, showering, tying shoe laces, moving about the house, climbing stairs, getting out of bed, using the bathroom, shopping, preparing meals, eating, household tasks, walking down the street, using public transportation, driving, going to the doctor, doing physical exercise and intimate relations), some of which is not captured by validated tools. The Functional Limitation Index was generated by adding the non-weighted degree of functional limitation of all activities using a Likert scale of $0-3$ (where $0=$ none, $1=$ low, $2=$ medium and $3=$ high limitation). Total scores indicated low (0-17), medium (18-35) or high (36-54) degree of limitation in daily life. Cronbach alpha of 0.97 demonstrated excellent internal reliability. ${ }^{211}$

\section{Mental health}

Mental disorder risk: assessed using the GHQ-12. It is a measure of psychological distress comprising symptoms of anxiety, social dysfunction and loss of confidence. ${ }^{12}$ It is not a psychiatric diagnostic instrument but is a validated screening tool for identifying common mental problems in the general population. ${ }^{13}$ Part of the value of the GHQ-12 is that it has been widely used across many long-term conditions, it has not yet been validated specifically in rheumatological conditions. The GHQ-12 scale consist of 12 items (1: Able to concentrate; 2: Loss of sleep over worry; 3: Playing a useful part; 4: Capable of making decisions; 5 : Felt constantly under train; 6: Couldn't overcome difficulties; 7: Able to enjoy day-to-day activities; 8: Able to face problems; 9: Feeling unhappy and depressed; 10: Losing confidence; 11: Thinking of self as worthless; 12: Feeling reasonably happy) to assess mental health problems during the previous 4 weeks using a 4-point Likert scale (less than usual, no more than usual, rather more than usual or much more than usual). Total GHQ-12 scores range between 0 and 36 , with higher scores reflecting an increased the risk of mental disorders. To determine mental disorder risk among patients with axSpA, the Likert scale was transformed to $0,0,1,1$, and the threshold for mental disorder risk set at $\geq 3$ as supported by literature. ${ }^{9}$

The GHQ-12 is a screening measure for identifying minor psychiatric disorders in the general population, used to encompass common symptoms of anxiety social dysfunction and loss of confidence. ${ }^{12}$ It is not a diagnostic instrument.

Mental health comorbidity: patients were asked to selfreport if they had been previously diagnosed with anxiety or depression.

\section{Statistical analysis}

Bivariate analyses were conducted to determine possible relationships between the study variables and mental health (GHQ-12 cut-off). For quantitative variables (age, BASDAI and Functional Limitation Index), the Mann-Whitney test was used to evaluate differences in the distribution of variables between GHQ-12 cut-off points $(<3$ and $\geq 3)$. For categorical variables (gender, relationship status, educational level, job status, patient organisation membership, BASDAI cut-off, depression diagnosis and anxiety diagnosis), a $\chi^{2}$ test was used to compare the distribution of variables between GHQ-12 cut-off points.

Variables that showed statistical significance $(\mathrm{p}<0.05)$ in the bivariate analysis were introduced in the binary logistic multivariable regression model: age (years), sex (female), job status (unemployed or sick leave), anxiety diagnosis (yes), depression diagnosis (yes), BASDAI cut-off ( $\geq 4)$ and Functional Limitation Index (0-54). Each variable was introduced individually into the model to determine which was associated with mental disorder risk.

Data were analysed using IBM SPSS software, V.25 and differences were considered statistically significant at the $5 \%$ level.

\section{RESULTS}

A total of 2,166 participants were included in this analysis, of whom $1314(60.7 \%)$ were classified as at risk of mental disorders based on their GHQ-12 score, the mean of which was $4.8 \pm 4.0$. See table 1 for a summary of the sample characteristics.

Mental disorder risk was unevenly distributed among countries, with Russia having the worst mental health (75.1\%) followed by France (70.5\%). Austria (41.5\%) 
Table 1 Socio-Demographic data, disease outcomes, treatment, and mental health sample characteristics

\begin{tabular}{lc}
\hline Variables & Means \pm SD or $\mathbf{n}(\%)$ \\
\hline Sociodemographic & \\
\hline Age, years & $43.4 \pm 12.6$ \\
\hline Sex, male & $777(35.9 \%)$ \\
\hline Having a partner $(\mathrm{n}=2,165)$ & $1,716(79.3 \%)$ \\
\hline Education level, university studies & $1,119(51.7 \%)$ \\
\hline Job status, employee $(\mathrm{n}=2,051)$ & $1,132(52.3 \%)$ \\
\hline Patient organisation membership & $806(37.2 \%)$ \\
\hline Disease outcomes & \\
\hline BASDAl (0-10) & $5.4 \pm 2.0$ \\
\hline Global Limitation Index $(0-54)$ & $14.25 \pm 11.8$ \\
\hline Treatment & $1,272(77.6 \%)$ \\
\hline NSAID ( $=1,639)$ & $652(40.8 \%)$ \\
\hline Synthetic DMARD $(n=1,597)$ & $709(43.3 \%)$ \\
\hline Biologic DMARD $(n=1,636)$ & \\
\hline Mental health & $610(30.0 \%)$ \\
\hline Depression diagnosis $(n=2,034)$ & $674(33.1 \%)$ \\
\hline Anxiety diagnosis $(n=2,038)$ & $4.8 \pm 4.0$ \\
\hline GHQ-12 (0-12) & $1,314(60.7 \%)$ \\
\hline Risk of mental disorders $(\mathrm{GHQ}-12 \geq 3)$ & \\
\hline Results are & \\
\hline
\end{tabular}

Results are based on 2,166 respondents unless otherwise stated and are expressed as mean \pm SD or $n(\%)$.

BASDAI, Bath Ankylosing Spondylitis Disease Activity Index; DMARD, disease-modifying antirheumatic drug; GHQ-12, 12 item General Health Questionnaire; NSAID, nonsteroidal antiinflammatory drug.

and Switzerland $(42.5 \%)$ reported among the lowest (figure 2). Across Europe, $30.0 \%$ of participants reported previous experience of depression while $33.1 \%$ reported previous anxiety.

The bivariate analyses showed that mental disorder risk (GHQ-12 $\geq 3$ ) was significantly associated with the following variables: younger age, female sex, unemployment, temporary sick leave, permanent sick leave, previous anxiety diagnosis, previous depression diagnosis, higher level of disease activity (accounted by both the overall BASDAI score and a greater proportion of participants scoring $>4$ on the BASDAI scale), and worse functional limitation $(p<0.001$ for all comparisons). See table 2 for further details.

In the binary multivariable logistic regression, worse mental health was associated with younger age, female sex, being on unemployment or sick leave, a comorbid diagnosis of anxiety or depression, increased disease activity and worse functional limitation. Furthermore, the factors significantly associated with risk of mental disorders were: disease activity $(\mathrm{OR}=2.80 ; 95 \% \mathrm{CI}=2.17$ to 3.61$)$, being diagnosed with anxiety $(\mathrm{OR}=2.39 ; 95 \%$ $\mathrm{CI}=1.78$ to 3.19$)$ or depression $(\mathrm{OR}=2.42 ; 95 \% \mathrm{CI}=1.79$ to 3.28), being unemployed or on sick leave $(\mathrm{OR}=1.98$; $95 \% \mathrm{CI}=1.53$ to 2.56 ), higher functional limitation in

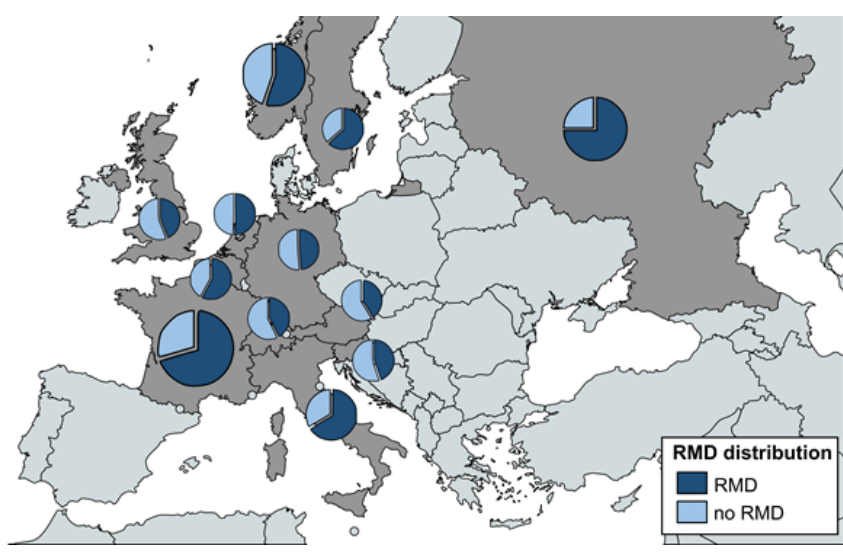

Figure 2 European sample distribution of patients for each EMAS country stratified by the presence of mental disorder risk. Based on 2166 respondents. sector diagrams show the proportion of patients with axial spondyloarthritis at worse mental health in the participating countries. Sector diagram size represents relative sample size of each EMAS participating country. EMAS, European Map of Ankylosing Spondyloarthritis; RMD, risk of mental disorders (defined as the 12-Item General Health Questionnaire Score $\geq 3$ ).

daily activities $(\mathrm{OR}=1.02 ; 95 \% \mathrm{CI}=1.01$ to 1.03$)$ and younger age $(\mathrm{OR}=0.97 ; 95 \% \mathrm{CI}=0.97$ to 0.98$)$ (table 3$)$.

\section{DISCUSSION}

The results of the present study of patients with axSpA in Europe show mental disorder risk in $60.7 \%$, according to the GHQ-12 scale. In the multivariable analyses, the factors significantly associated with the risk of mental disorders are: disease activity, being diagnosed with anxiety or depression, being unemployed or on sick leave, greater functional limitation in daily activities and being younger.

Furthermore, almost one-third reported previous experience of anxiety $(30.0 \%)$ or depression $(33.1 \%)$. These figures are six times greater among patients with axSpA in comparison with the general population in Europe, where the presence of anxiety and depression disorders was estimated at $5.4 \%$ and $4.5 \%$, respectively. ${ }^{14}$

The high proportion of those experiencing mental disorder symptoms confirms a relationship between axSpA and poorer mental health. However, in clinical practice, there remains a gap in the systematic assessment of mental health which may be leading to an underdiagnosis and undertreatment of common mental disorders among patients with axSpA. We argue this compromises the quality of patient care and affects health outcomes.

Higher disease activity is likely to leave patients with axSpA feeling anxious and distressed about their uncontrolled pain, fatigue and joint stiffness. The relationship between disease activity and poor mental health is bidirectional, with worsening mental health also influencing disease activity. ${ }^{15-18}$ This can make patient management in clinical practice a challenge. However, clinicians well-trained in communication skills can adopt a more patient-centred approach to ask key questions that elicit 
Table 2 Bivariate analysis of factors associated with mental disorder risk by GHQ-12 cut-off

\begin{tabular}{|c|c|c|c|}
\hline \multirow[b]{2}{*}{ Factors } & \multicolumn{2}{|c|}{ Mean \pm SD or $\mathrm{n}(\%)$} & \multirow[b]{2}{*}{$P$ value } \\
\hline & GHQ-12<3 & GHQ-12 $\geq 3$ & \\
\hline Age, years & $46.0 \pm 13.4$ & $41.7 \pm 11.8$ & $<0.001^{*}$ \\
\hline Sex & & & $<0.001^{*}$ \\
\hline Male & $359(42.1)$ & $418(31.8)$ & \\
\hline Female & $493(57.9)$ & $896(68.2)$ & \\
\hline \multicolumn{2}{|c|}{ Having a partner $(n=2,165)$} & & 0.345 \\
\hline Yes & $684(80.3)$ & 1,032 (78.6) & \\
\hline No & $168(19.7)$ & $281(21.4)$ & \\
\hline \multicolumn{2}{|l|}{ Education level } & & 0.606 \\
\hline $\begin{array}{l}\text { No schooling } \\
\text { completed }\end{array}$ & $6(0.7)$ & $17(1.3)$ & \\
\hline Primary school & $55(6.5)$ & $89(6.8)$ & \\
\hline High school & $350(41.1)$ & $530(40.3)$ & \\
\hline University & $441(51.8)$ & $678(51.6)$ & \\
\hline \multicolumn{2}{|l|}{ Job status $(n=2,051)$} & & $<0.001^{*}$ \\
\hline Employed & $519(63.8)$ & $613(49.6)$ & \\
\hline Temporary sick leave & $44(5.4)$ & 197 (15.9) & \\
\hline Permanent sick leave & $65(8.0)$ & $163(13.2)$ & \\
\hline Retired & $102(12.5)$ & $65(5.3)$ & \\
\hline Early retirement & $11(1.4)$ & $22(1.8)$ & \\
\hline Unemployed & $22(2.7)$ & $93(7.5)$ & \\
\hline Homemaker & $36(4.4)$ & $35(2.8)$ & \\
\hline Student & $15(1.8)$ & $35(2.8)$ & \\
\hline \multicolumn{2}{|c|}{ Patient organisation membership } & & 0.652 \\
\hline Yes & $322(37.8)$ & $484(36.8)$ & \\
\hline No & $530(62.2)$ & $830(63.2)$ & \\
\hline BASDAI (0-10) & $4.6 \pm 2.0$ & $6.0 \pm 1.8$ & $<0.001^{*}$ \\
\hline \multicolumn{4}{|l|}{ BASDAI cut-off } \\
\hline BASDAI $<4$ & $321(37.7)$ & $163(12.4)$ & $<0.001^{*}$ \\
\hline BASDAI $\geq 4$ & $531(62.3)$ & $1,151(87.6)$ & \\
\hline $\begin{array}{l}\text { Global Limitation } \\
\text { Index (0-54) }\end{array}$ & $10.8 \pm 10.2$ & $16.5 \pm 12.1$ & $<0.001^{*}$ \\
\hline \multicolumn{2}{|c|}{ Depression diagnosis $(n=2,034)$} & & $<0.001^{*}$ \\
\hline Yes & $113(14.2)$ & $561(45.2)$ & \\
\hline No & $685(85.8)$ & $679(54.8)$ & \\
\hline \multicolumn{2}{|c|}{ Anxiety diagnosis $(n=2,038)$} & & $<0.001^{*}$ \\
\hline Yes & $100(12.5)$ & $510(41.3)$ & \\
\hline No & $700(87.5)$ & $724(58.7)$ & \\
\hline
\end{tabular}

BASDAI, Bath Ankylosing Spondylitis Disease Activity Index; GHQ-12, 12-item General Health Questionnaire.

the extent of the impact. For example, questions phrased as 'which is the most problematic to you, the physical symptoms or the impact the condition has on your life' with a follow-up of 'which aspect is most problematic at the moment' and 'if you could change one aspect, what would you change?' can guide the clinicians focus for treatment. $^{19}$
Our analysis showed that mental disorder risk is associated with a previous diagnosis of anxiety or depression as well as being unemployed or on sick leave, in both the bivariate and multivariable regression. The link with previous diagnosis of anxiety and depression served to validate the appropriateness of using the GHQ-12 scale. The data illustrated that patients with axSpA with high levels of distress were more likely to be unemployed or require sick leave and similarly, patients with axSpA who are either unemployed or on sick leave were more likely to develop mental disorders.

We confirmed the previously documented association between disease activity and unemployment/sick leave among patients with axSpA, ${ }^{20}$ but on larger scale. We now believe it is critical to optimise axSpA care by adopting a holistic approach to patient management to address these wider consequences.

Of course, the primary role of the rheumatologist is to control disease activity as it influences all aspects of the patient's life. However, it is also important to systematically assess mental health in rheumatology practice and facilitate early referral to mental health specialists when needed. This could be supported through enhanced clinician education and introduction of simple screening tools, such as the GHQ-12, which has been used extensively in non-psychiatric clinical settings. ${ }^{13}$

EMAS was the largest survey carried out to date for patients with axSpA, capturing differences in the experience of patients with axSpA across the European continent. Results of the present study confirmed the findings of the previous similar study carried out in Spain. ${ }^{9}$ Compared with the Spanish study, our study shows even higher rates of common mental disorders than the Spanish sample (33.1\% vs $28.2 \%$ in the case of anxiety and $30.0 \%$ vs $20.8 \%$ in the case of depression). Additionally, mental disorder risk (GHQ-12 scores $\geq 3$ ) was present in $45.6 \%$ of patients in Spain and $60.7 \%$ in Europe. ${ }^{9}$ The difference in the prevalence of mental disorder risk presented by the different EMAS countries may be due to socioeconomic characteristics and healthcare resources available in each of these countries. However, the inclusion of all these countries helps us to gain a better geographical coverage of mental health in the different European countries.

As the survey questions were cocreated with patients, we are confident the data truly reflects the experience of patient with axSpA. However, EMAS is not without criticism, the information came from self-reported data, with no clinician confirmed assessments with the limitations that imply. Second, we appreciate the problem of using non-validated scales or indices for assessing functional limitations in daily life and stiffness. We took the decision to use the measures in this study because in the early phase of this work patients expressed their frustration at the limitations of other scales or indices that did not capture the full extent of the impact that living with axSpA had on their lives. Cronbach's alpha coefficient obtained for the measures used in our study 
Table 3 Binary logistic regression to predict factors associated with the risk of mental disorders

\begin{tabular}{|c|c|c|c|c|}
\hline \multirow[b]{2}{*}{ Variables } & \multicolumn{2}{|c|}{ Univariable logistic regression } & \multicolumn{2}{|c|}{ Multivariable logistic regression } \\
\hline & OR & $95 \% \mathrm{Cl}$ & OR & $95 \% \mathrm{Cl}$ \\
\hline Age (in years) & 0.973 & 0.966 to 0.980 & 0.974 & 0.966 to 0.982 \\
\hline Sex (female) & 1.561 & 1.305 to 1.867 & 1.031 & 0.825 to 1.288 \\
\hline Job status (unemployed or sick leave) & 3.013 & 2.418 to 3.753 & 1.979 & 1.532 to 2.557 \\
\hline Depression diagnosis (yes) & 4.931 & 3.886 to 6.257 & 2.420 & 1.789 to 3.279 \\
\hline Anxiety diagnosis (yes) & 5.008 & 3.986 to 6.293 & 2.386 & 1.784 to 3.191 \\
\hline BASDAI $(\geq 4)$ & 4.269 & 3.444 to 5.291 & 2.801 & 2.173 to 3.610 \\
\hline Global Limitation Index (0-54) & 1.046 & 1.038 to 1.055 & 1.021 & 1.011 to 1.031 \\
\hline
\end{tabular}

Data are based on 1,895 respondents.

BASDAI, Bath Ankylosing Spondylitis Disease Activity Index.

indicated the acceptability of these instruments. Finally, the possibility of selection bias cannot be ruled out for those countries that included a smaller sample size. In addition, the non-validated Functional Limitation Index was used to assess functional limitation in 18 activities of daily life, assessing the degree of functional limitation of all activities using a Likert scale of $0-3$, obtaining a scale from 0 to 54, being 0-17 low, 18-35 medium and 36-54 high degree of limitation in daily life. The use of Functional Limitation Index was done out of necessity as the Assessment of SpondyloArthritis International Society Health Index (ASAS-HI) scale was not available at the time of our study. The ASAS-HI measures functioning and health across 17 aspects regarding functional limitation in daily activities with two possible answers for each: agree or disagree of health, resulting in a score ranging from 0 to 17 , in which a lower score indicates a better functioning and health status. However, the Cronbach alpha coefficient supports the reliability of the Functional Limitation Index. ${ }^{211}$ The large numbers in our survey has given us confidence that the findings are representative of the subpopulations in those geographical areas. Given the nature of the survey, which was not targeted at specific individuals, we have no way of knowing how many people saw the notice and chose not to respond. Furthermore, the possibility of selection bias cannot be ruled out for those EMAS countries that included a smaller sample size and for those characterised by a dominant form of patient recruitment. However, as this was a cross-sectional study, we cannot establish causality between the results obtained and the results should be interpreted with caution. Finally, the use of the GHQ-12 in patients with underlying physical conditions is not without criticism. We chose this measure because it allows us comparison with a similar population in previously published work and, although being more conservative, we adopted a higher cut-off score indicating distress and we recognise the limitation of the measure and recommend disease-specific validation is performed in future research.

\section{CONCLUSION}

This study shows European patients with axSpA exhibit a disproportionately high levels of common mental disorders, compared with the general population. Worst mental health appears to increase with disease activity and is linked to employment status and the ability to perform daily and work-related tasks. Together, these findings highlight the need to optimise disease management of the whole person, ensuring disease activity is well-controlled but also addressing high levels of distress in those who require it. Systematic clinical assessments of mental health, clinician education on recognising and monitoring the mental health aspects of axSpA and prompt referral to mental health specialists are critical strategies to ensure optimal health of patients with axSpA.

\section{Twitter Marco Garrido-Cumbrera @MarcoGarridoCum}

Acknowledgements The authors acknowledge the EMAS working group. The EMAS project is a collaboration led by the Health \& Territory Research group of the University of Seville, the Ankylosing Spondylitis International Federation, and a steering committee composed of patient representatives and internationally recognised rheumatologists, psychologists, and researchers specialised in axSpA The authors would like to thank all patients who participated in the study.

Collaborators We thank the researcher José Correa-Fernández for reviewing the manuscript.

Contributors All authors have contributed equally. MG-C is responsible for the overall content and acts as guarantor for this manuscript.

Funding This study was supported by Novartis Pharma AG.

Map disclaimer The inclusion of any map (including the depiction of any boundaries therein), or of any geographic or locational reference, does not imply the expression of any opinion whatsoever on the part of BMJ concerning the legal status of any country, territory, jurisdiction or area or of its authorities. Any such expression remains solely that of the relevant source and is not endorsed by BMJ. Maps are provided without any warranty of any kind, either express or implied.

Competing interests EMAS was funded by Novartis Pharma AG. All authors have received honoraria from Novartis Pharma AG for participating in EMAS. DP has received unrelated research grants from AbbVie, Merck Sharp \& Dohme (MSD), Novartis and Pfizer, and unrelated honoraria from AbbVie, Bristol Myers Squibb (BMS), Celgene, Janssen, Lilly, MSD, Novartis, Pfizer, Roche and UCB. VN-C has received unrelated honoraria or research grants from AbbVie, BMS, Janssen, Lilly, MSD, Novartis, Pfizer, Roche and UCB. LC is employee of Novartis Pharma AG.

SM has received unrelated honoraria from GlaxoSmithKline and Bayer. CB has received unrelated honoraria from AbbVie, Amgen, Janssen, Lilly, Novartis and Pfizer.

Patient consent for publication Not applicable.

Provenance and peer review Not commissioned; externally peer reviewed. 
Data availability statement The authors confirm that the data supporting the findings of this study are available within the article.

Open access This is an open access article distributed in accordance with the Creative Commons Attribution Non Commercial (CC BY-NC 4.0) license, which permits others to distribute, remix, adapt, build upon this work non-commercially, and license their derivative works on different terms, provided the original work is properly cited, appropriate credit is given, any changes made indicated, and the use is non-commercial. See: http://creativecommons.org/licenses/by-nc/4.0/.

ORCID iDs

Marco Garrido-Cumbrera http://orcid.org/0000-0001-9727-1189

Denis Poddubnyy http://orcid.org/0000-0002-4537-6015

\section{REFERENCES}

1 Kiltz U, van der Heijde D. Health-related quality of life in patients with rheumatoid arthritis and in patients with ankylosing spondylitis. Clin Exp Rheumatol 2009;27:S108-11.

2 Garrido-Cumbrera M, Poddubnyy D, Gossec L, et al. The European Map of Axial Spondyloarthritis: Capturing the patient Perspectivean analysis of 2846 patients across 13 countries. Curr Rheumatol Rep 2019;21:1-9.

3 Zhao S, Thong D, Miller N, et al. The prevalence of depression in axial spondyloarthritis and its association with disease activity: a systematic review and meta-analysis. Arthritis Res Ther 2018:20:140

4 Durmus D, Sarisoy G, Alayli G, et al. Psychiatric symptoms in ankylosing spondylitis: their relationship with disease activity, functional capacity, pain and fatigue. Compr Psychiatry 2015;62:170-7.

5 Chan CYY, Tsang HHL, Lau CS, et al. Prevalence of depressive and anxiety disorders and validation of the hospital anxiety and depression scale as a screening tool in axial spondyloarthritis patients. Int J Rheum Dis 2017;20:317-25.

6 Meesters JJL, Petersson IF, Bergman S, et al. Sociodemographic and disease-related factors are associated with patient-reported anxiety and depression in spondyloarthritis patients in the Swedish SpAScania cohort. Clin Rheumatol 2014;33:1649-56.
7 Xu X, Shen B, Zhang A, et al. Anxiety and depression correlate with disease and quality-of-life parameters in Chinese patients with ankylosing spondylitis. Patient Prefer Adherence 2016;10:879-85

8 Martindale J, Smith J, Sutton CJ, et al. Disease and psychological status in ankylosing spondylitis. Rheumatology 2006;45:1288-93.

9 Garrido-Cumbrera M, Delgado-Domínguez CJ, Gálvez-Ruiz D, et al. The effect of axial spondyloarthritis on mental health: results from the atlas. J Rheumatol 2019;46:1284-9.

10 Garrido-Cumbrera M, Gálvez-Ruiz D, Chacón García J. Atlas of axial spondyloarthritis in Spain 2017. profile of the disease. Max Weber Institute, 2017.

11 Garrido-Cumbrera M, Navarro-Compán V, Zarco P, et al. Atlas of axial spondyloarthritis in Spain 2017: study design and population. Reumatol Clin 2019;15:127-32.

12 Hankins $M$. The reliability of the twelve-item general health questionnaire (GHQ-12) under realistic assumptions. BMC Public Health 2008;8:7.

13 Goldberg D, Williams P. A user's guide to the. UK: General Health Questionnaire, 1988.

14 OECD/EU. Health at a glance: Europe 2018 state of health in the EU cycle, 2018.

15 Baysal O, Durmuș B, Ersoy Y, et al. Relationship between psychological status and disease activity and quality of life in ankylosing spondylitis. Rheumatol Int 2011;31:795-800.

16 Brionez TF, Assassi S, Reveille JD, et al. Psychological correlates of self-reported functional limitation in patients with ankylosing spondylitis. Arthritis Res Ther 2009;11:R182.

17 Domínguez CJD, Ugalde PF, Vilchez DR, et al. Positive and negative affective states and disease activity in ankylosing spondylitis. Rheumatol Int 2015;35:519-24.

18 Jiang $\mathrm{Y}$, Yang $\mathrm{M}, \mathrm{Wu} \mathrm{H}$, et al. The relationship between disease activity measured by the BASDAI and psychological status, stressful life events, and sleep quality in ankylosing spondylitis. Clin Rheumatol 2015;34:503-10.

19 Chisholm A, Nelson PA, Pearce CJ, et al. Motivational interviewingbased training enhances clinicians' skills and knowledge in psoriasis: findings from the Pso Well ${ }^{\circledR}$ study. Br J Dermatol 2017;176:677-86.

20 Garrido-Cumbrera M, Bundy C, Navarro-Compán V, et al. PatientReported impact of axial spondyloarthritis on working life: results from the EMAS survey. Arthritis Care Res 2020;19. doi:10.1002/ acr.24426. [Epub ahead of print: 19 Aug 2020]. 